\title{
Article \\ Authentic Student Laboratory Classes in Science Education
}

\author{
Jurgen Schulte ${ }^{1,+}(\mathbb{D}$ \\ 1 University of Technology Sydney; jurgen.schulte@uts.edu.au \\ + Current address: School of Mathematical \& Physical Sciences, University of Technology Sydney, Ultimo \\ NSW 2007, Australia
}

\begin{abstract}
The traditional hands-on nature in science laboratory classes creates a sense of immediacy and a presence of authenticity in such learning experiences. The handling of physical objects in a laboratory class, and the immediate responses provided by these experiments, are certainly real-live observations, yet may be far from instilling an authentic learning experience in students. This paper explores the presence of authenticity in hands-on laboratory classes in introductory science laboratories. With our own laboratory program as a backdrop we introduce four general types of hands-on laboratory experiences and assign degrees of authenticity according the processes and student engagement associated with them. We present a newly developed type of hands-on experiment which takes a somewhat different view of the concept of hands-on in a laboratory class. A proxemics-based study of teacher-student interactions in the hands-on laboratory classes presents us with some insights into the design of the different types of laboratory classes and the pedagogical presumptions we made. A step-by-step guide on how to embed industry engagement in the curriculum and the design of an authentic laboratory program is presented to highlight some minimum requirement for the sustainability of such program and pitfalls to avoid.
\end{abstract}

Keywords: authentic learning, work integrated learning, curriculum development, laboratory classes, proxemics

\section{Introduction}

The development of new experiments is a large undertaking for science educators in secondary and early tertiary education, which is often accompanied by constraints due to time and budget limitations and sometimes due to restrictions imposed by an overarching pedagogical framework. This becomes an even more challenging endeavor when an entire laboratory program is to be redesigned to meet certain desired educational outcomes.

There are some disciplinary skills that need to be conveyed such as the application of disciplinary concepts, general laboratory specific skills and general disciplinary specific instrumentation skills. Then there are some soft-skills to be developed that are nurturing a larger pedagogical framework within the educational organization or to meet a national education policy. Common soft-skills in this context are working in a team and team and time management; verbal and written skills, presentation skills; and discipline specific reporting skills.

Ideally, in the development of a new science laboratory program, pedagogical aspects should be considered first before considering the curriculum and technical aspects of the laboratory design. The supporting drivers here are the opportunities for all students to be positively engaged in the program, the program's credibility and its relevance as perceived by students. Motivated and well engaged students have a positive and often long lasting learning experience and generally tend to present good learning outcomes.

Student motivation is driven by their individual interest and curiosity, it can also be driven by challenges that go beyond the textbook script. When designing an activity, the task to be performed should also consider students' intellectual preparedness, pathways and past experience (e.g., mature 
students, students with work experience, adults). In that, a high level of intellectual conceptualization adds to the credibility and, if placed in a situated context, adds to the authenticity of the task as well as the relevance of the learning context. This becomes even more important when students are expected to learn skills that appear to be peripheral to the immediate disciplinary content, yet form an important foundation to the graduate knowledge, e.g., engineering students, who as part of their degree requirements take classes in physics, chemistry, mathematics or finance.

This paper takes a closer look at the conceptual and pedagogical aspect of authentic student learning experiences with reference to our own physics laboratory program. The considerations in this paper are of quite general nature and may be easily transferred to other physical or life sciences laboratory programs. In chapter 2 , we discuss the concept of authenticity in context of student learning and the characteristic elements that constitute authenticity in a student laboratory environment. Chapter 3 explores some typical indicators to identify learning patterns in a laboratory environment, how these might be used to identify and measure authenticity in a qualitative way, and how in an authentic laboratory task learning outcomes may be assessed. In chapter 4, we elucidate some learning and interaction dynamics in the laboratory classes using proxemics measurements as tool to identify levels of authenticity. In the last part of this paper, chapter 5, we present some guidance for the design process of an authentic laboratory program based on the evaluation of the design of the authentic learning experiences in one of our own laboratory programs.

\section{Authentic Learning Experiences}

In the early 21st century science textbooks kept a narrow focus on pure disciplinary knowledge, almost as if there was an assumption that all science students aspire to a similar academic career as the authors of these books. This view slowly changed in the 1990's with the recognition that the majority of university science students are not aiming for a academic career and the narrow focus on content with a purely academic end goal did not appeal to students' motivation. By that time, students already enjoyed an increasing science technology awareness due to readily accessible digital media. The difference in the evolution of highschool textbook aligned teaching and first year science education in higher education is marginal. Often, courses rely on heavily prescribed curricula built around certain textbook content. Prompted by the realization that there is more to a science education than an academic career as end goal, a gradual shift in pedagogical thinking occurred with the desire to make science education more accessible to students by introducing more traceable links to real life; a degree of authenticity. Contemporary science textbooks now include elements of authenticity built into the wording of practice problems as well as in illustrations of daily life applications. While the weaving in of authenticity through wording and readily recognizable real life related illustrations is acknowledging the need for science skills to be seen in a more than purely academic context, there is a risk that such surface approach is undervaluing the intellectual academic maturity of the intended student reader, who may find such word or image associations rather stretched and artificial than convincingly authentic.

Real life relevance, as part of the learning experience in higher education and authenticity in learning and teaching, has become a serious formal requirement in Australian higher education with the formal introduction of graduate attributes at the turn of the millennium [1]. The Department of Education Training and Youth Affairs (DETYA) required higher education institutions to articulate the graduate attributes that their courses aim to develop. That is, professional bodies and employers can expect that graduates graduating from a particular course have acquired the named graduate attributes. For example, the graduate attributes associated with the science faculty in our university are: disciplinary knowledge; research, inquiry and critical thinking; professional, ethical and social responsibility; reflection, innovation and creativity; communication; Aboriginal and Torres Strait Islander knowledges and connection with Country [2].

What are the characteristics of an authentic learning experience? Authenticity in higher education is generally associated with a disciplinary context placed in a real-world activity, i.e., something 


\begin{abstract}
hands-on and done in practice or seen in association with some out-of-class activity. This alone though does not make a learning experience authentic. The experience itself should also be seen by the professional (educator, professional in the work force) as authentic; it is equally important that it also perceived by the student learners as credibly authentic.
\end{abstract}

Following the work by Reeves et al. [3] it can be noted that from a work professional point of view, an authentic learning experience should have some relevance outside the classroom experience; it should be open ended; have a complex problem to solve that requires higher order thinking; there may be many valid solutions to the task; there may be different technical approaches to solving the problem; the task covers multiple disciplinary concepts; the task encourages small team working; and there is a reflective evaluation of the solution process and outcome, similar to what a professional would experience in a non-academic work environment.

From a student learner point of view, the task and the context within are of credible authenticity, that is, students can believe and verify that such task is indeed commonly performed by professionals in the workforce. In such a setting, student learners have the opportunity to explore, discuss, and meaningfully construct concepts and relationships that involve real-world problems which are interesting and relevant to them [4]. A theoretical model to support such situated learning in a science education, where the credibility aspects from the student perspective was taking into account was presented in a recent discourse by Van Vorst et al. [5].

A laboratory class as part of a standard science curriculum is an opportunity for a hands-on experience for students, where hands-on is often implying some degree of authenticity that goes beyond the implied authentic approach taken in textbooks. Here, the textbook science is transferred from an abstract or imaginary context to a related hands-on, simulated real-world experiment where the underlying science is seen to become authentic in that process. The authenticity in student laboratory experiments though has changed its connotation over the past decades, from a narrow academic science topic at hand in the 1990's, to the current view of seeing the situated experience within a larger disciplinary professional context. It is this type of 'larger context' authenticity that we'd like to address in the following discussion. A hands-on experience although is not necessarily a pre-requisite for an authentic laboratory experience. An example of an authentic laboratory experience without student hands-on activity is presented in chapter 3.

Situated learning has been instrumental in linking theoretical textbook knowledge with applications of the knowledge in real-world (or real-work) situations [6]. Situated learning provides an avenue for emphasizing the directly applicable part of knowledge and in that course extends the more fundamental or theoretical knowledge base. In a situated learning environment, students have the opportunity to apply their experience and knowledge in ways that are grounded in real world scenarios $[7,8]$. Alternating cycles of theory (lectures) and practice (laboratory class) are introduced to foster an episodic acquisition of knowledge [9]. Situated learning enables teachers to create curricula that also address the motivational aspects of learning in order to make STEM (Science, Technology, Engineering, Mathematics) topics more accessible to students [10]. A comprehensive discourse on the evolution and current view on situated learning in a physics context can be found in Bennett, Lubben \& Hogarth [11].

In-depth disciplinary knowledge and skills are what employers expect by default from their graduate recruits. In addition to these assumed skills, employers expect graduates to present some knowledge across disciplines and social or economic context as well as skills in people and process management [12]. These non-core disciplinary skills, or soft-skills, often become more relevant when graduates are seeking employment in areas that are peripheral to the academic core of their degree course, or when the landscape of the relevant profession is changing rapidly. Authentic learning environments 
are inherently multifaceted and multidisciplinary. They foster the development of an intellectual capability of readily transforming core disciplinary knowledge and skills from a narrow academic performance context to a larger out of academia yet discipline related context.

\section{Authentic teaching and learning in science laboratory classes}

There has been a long tradition in the development of first year university student experiments in science that aimed to replicate fundamental experiments carried out by previous scientist in the early days of modern scientific discovery. This is where academics tend to teach content in a purely academic context to prepare students for experimental work relevant in an academic environment. In these traditional type of experiments, students learn a prescribed collection of discipline related facts and follow step-by-step instructions to become familiar research steps that previous scientist took [13]. Naturally, these types of traditional experiments offer only limited opportunity for self-directed inquiry, critical thinking, independent experiment design thinking or context related problem solving.

In an attempt to engage students more actively in the learning process and to foster more critical thinking in science education, traditional experiments were modified to allow for episodes of inquiry built on top of the prescribed traditional academic process. Although this new inquiry based approached was welcomed by students and teachers alike as refresher to the repetitive processes in traditional student experiments [14], the novelty continued to be dominated by a perceived need, by educators to prescribe and control the experimental process as well as to have all students work and complete each experiment in a synchronized fashion.

Doing actual scientifically motivated experimental work in a professional working environment will always be quite different from the simulation of such task in an educational environment unless the purpose of the task and its performance and consequences are assessed in similar ways. Hence, authenticity in an educational context will always be limited, especially at an introductory level. Authenticity in that respect may then be measured by the creditability of the authentic learning experience as judged by the educator and professional and as perceived by the student learner.

The question arises then, what aspects in the design of a student laboratory program should educators consider when creating a credible authentic learning experience?

Over the years of designing and teaching introductory experimental laboratory programs we identified three main authenticity driving forces; the role of the teacher in the laboratory class, the interactions that students engage in, and the role of external agents.

In an authentic learning environment the teacher takes one a background role, more like a mentor than a leader issuing directives to control the flow of the activity. Working in small groups and engaging in discussions is encouraged $[15,16]$, and teachers acknowledge that such in- and inter-group discussion may elevate the level of noise in the classroom. Once the teacher steps back from controlling the experimental proceedings, the process flow of the activity is no longer under the complete control of the teacher. Students have then the opportunity to take on some ownership of the experimental work and with that an immediate responsibility for their actions, i.e., intellectually, creativity-wise and socially. Responsibility always requires a third party against which it can be measured or benchmarked. This is where authentic, external performance processes may be brought in to contribute to the authenticity and credibility of the experimental task. That is, the task performed has a strong relation to present concerns outside the class room and there is an external party involved in the evaluation of the task (peer review, supervisor, client, commissioning agent). In this process, peers for instance are then recognized as 'legitimate peripheral participants' [17] in a community of practice. Students become familiar with stakeholders outside the disciplinary knowledge context and their discipline related expectations. 
Without a prescribed or controlled experimental process flow, it is likely that students will arrive at different experimental outcomes or arrive at similar outcomes albeit via different pathways. In that sense, introducing authenticity by allowing ownership and responsibility, is also creating an inherently built in open-endedness in the learning experience. Such open-ended practical learning methods have been found to foster a good level of conceptual understanding and development of process skills even for low performing students [18]. The intellectual challenge presented by an authentic learning experience may be higher, yet due to the multi-faceted entry points to the challenge more students can find a pathway to improve their disciplinary knowledge and skills.

Table 1. Experiment styles and characteristic features.

\begin{tabular}{|c|c|c|c|c|}
\hline & Traditional & Inquiry & Authentic (theory) & $\begin{array}{l}\text { Authentic } \\
\text { (hands-on) }\end{array}$ \\
\hline Equipment & fixed & fixed & $\begin{array}{l}\text { none, } \\
\text { fixed master only }\end{array}$ & self-selected \\
\hline $\begin{array}{l}\text { Experimental } \\
\text { Setup }\end{array}$ & fixed & fixed & $\begin{array}{l}\text { none, } \\
\text { fixed master only }\end{array}$ & self-selected \\
\hline Starting Point & fixed & fixed & self-selected & self-selected \\
\hline Procedure & prescribed & $\begin{array}{l}\text { guided and } \\
\text { prescribed }\end{array}$ & self-selected & self-selected \\
\hline Aim & $\begin{array}{l}\text { collect data, } \\
\text { confirm textbook } \\
\text { knowledge and } \\
\text { quantity }\end{array}$ & $\begin{array}{l}\text { collect data, } \\
\text { confirm textbook } \\
\text { knowledge and } \\
\text { quantity }\end{array}$ & $\begin{array}{l}\text { question validity } \\
\text { of textbook } \\
\text { knowledge }\end{array}$ & $\begin{array}{l}\text { solve a complex } \\
\text { problem }\end{array}$ \\
\hline Outcome & fixed & fixed & $\begin{array}{l}\text { self-selected } \\
\text { textbook } \\
\text { knowledge } \\
\text { expansion }\end{array}$ & open variety \\
\hline
\end{tabular}

How does an authentic learning experience translate into a science (e.g. physics) laboratory class and how does that affect students' learning processes?

In our laboratory program we distinguish four different styles of laboratory learning experiences. In a Traditional or standard science laboratory class, experiments are designed for students to acknowledge predefined facts about a topic and well defined procedures to acquire experimental data about these facts with the aim to confirm another fact, often an equation or quantity from the textbook. Naturally, in order for the student to stay within the boundary of 'experiencing' these facts during class, the boundaries of the class design have to be well defined and a-priori fixed. For instance, the experimental setup is the same for all students and cannot be altered to ensure that all students learn the same facts and arrive at the same preset outcome (Table 1). In this type of learning experience it is assumed that students acquire knowledge by accumulating data in an experiment and associating this data with the science facts following the teacher's prescribed procedure. Students also learn about the mechanics of conducting a set experiment and collecting and evaluating data. These learning steps are then often repeated in subsequent laboratory classes, albeit within a different disciplinary context. In this kind of environment, all students work very much in sync, working alone or in small groups, and all are expected to completed their task with the same experimental outcome. Students are provided with step by step instructions to complete the experimental task, that is, settings for experimental equipment, sequence of steps to take in order to measure data about a fact and steps to take to evaluate 
the measured data. Students are then well instructed to complete the task without needing frequent affirmations throughout the process. However, later we will see that this does not seem to be the case and students appear to be more focused on procedural matters than conceptual understanding.

An Inquiry based learning experience allows for more initiative taken by students. This type of learning style was introduced in the 1990s to encourage independent thinking and some degree of reflection. Other learning attributes were added later to accommodate some insights from the emerging field the science of learning [19]. Here, we consider an early version of inquiry based learning in a laboratory class setting which is still quite common in many laboratory programs both in highschool and higher education. Students are provided with a set goal, that is, verifying a science fact by conducting an predefined experiment and taking measurements to collect data in order to substantiate a fact, formula or quantity mentioned in the textbook. The outcome of the experiment and the procedures taken are as well defined as per the traditional experiment. The experimental procedures are layed out in principle although not in as stepwise detail as in a traditional experiment (Table 1). Students are given some flexibility with respect to order of steps to conduct the experiment and hence some time is allowed for elements of exploration or inquiry, but it is very clear from the beginning that there is a certain path to follow. With that in mind the experimental setup has then to be very much the same for all students. Again, the general learning experience is that of measuring and collecting data with some variation allowed for playing with the sequence of conducting the experiment. By allowing some self-determined elements within their experimental investigation, episodes of inquiry are introduced which encourage some unguided experimentation and critical reasoning.

In order to allow students to engage in more active reflective thinking rather than the traditional fact accumulation of textbook theory, we developed a range of textbook theory focused authentic laboratory classes. We call these type of laboratory learning experiences Authentic (theory) learning experiences. This type of learning experience takes place in the normal laboratory class where a number of demonstration experiments have been set up. That is, students do not engage in setting up or conducting an experiment, instead they are asked to numerically predict the outcome of the experiments on display in the room, without further instructions as to how to go about this. Students are encouraged to have a close look at the experiment but are not allowed to touch or execute the experiment. For instance, a glass beaker filled with 1 liter of water is placed on a $1 \mathrm{~kW}$ electric heating plate with a thermometer next to it showing the room temperature. Students in teams of 3 to 4 are asked to predict the time it takes to bring the water to its boiling point. The textbook facts about the heat capacity of water and that the amount of heat taken up by water is proportional to the temperature increase can be readily looked up in the textbook. Conceptually, it is not a too difficult problem for students to link the textbook relation to the given specifications of the experiment in front of them. Students find the theoretical prediction fairly quickly, i.e., usually within the same time the water should have boiled in theory. Yet, the water does not boil at the predicted time. It does not even boil after twice the time has expired. Initially, students start to question the validity of their calculations and since the calculation is fairly simply they quickly realize that their correctly calculated answer may not apply to the real-world example in front of them. The reflective discussions within their small groups quickly reveal that in the textbook theory there are some underlying assumptions that do not translate to the reality as it unfolds in front of them. Eventually, students start to realize that a heater plate is a three-dimensional object and not a flat object as depicted in the textbook, i.e., only a small part of the top surface of the $1 \mathrm{~kW}$ heater plate is actually available for heating water through the bottom of the beaker. In addition, the sides and bottom parts of the heating plate dissipate part of the available heat energy straight into the room. Encouraged by this insight, students can make a rough estimate of how much power is actually available for heating the water and then redo their original 
textbook calculation to arrive at an answer which is very close to what has been observed in the class room.

In this learning experience the implied authenticity of a physics concept in the textbook in the familiar form of some real-world relating wording and an accompanying illustration or photo suggesting a real-world situation is placed in contrast with an actual physical situation in the room. Words from the textbook and the real-time acting objects in the room have to be reconciled with the students' conceptual understanding of the problem at hand. The actual physical power supplied from the mains to the heating plate has to find its way into the textbook equation, so does the thermometer reading of the room temperature and the final boiling stage of the water.

Initially, students find it somewhat challenging to reconcile the theory and relations in the textbook with the physical actions in front of them. With some inquiry based guidance though all students succeed with establishing a one-to-one mapping of textbook defined parameters and the physical action in front of them. This process entails some reflection with respect to the meaning of the terms and concepts in the textbook and how these manifest in their various occurrences in a live environment. Due to the inability of the textbook science to describe a seemingly similar scene playing out in front of them in real, students suddenly become an active part in the live scene, that is, they are no longer spectators and it requires an intervention on their own part to question and amend their textbook knowledge in order to confirm the truth playing out in front of them. A process of inquiry and immediate authentic and personal experience is started with students questioning their own correct application of textbook guided knowledge followed by a subsequent re-analysis of the experiment and an articulation of a remedial hypothesis to amend the textbook theory which may then explain the experienced outcome of the experiment.

Following the textbook knowledge that they thought they had mastered already and still failing to predict the outcome of a simple, directly related experiment created a situation where students were drawn into re-analyzing the textbook discipline knowledge in the context of an event they were personally involved in. A truly personal and authenticity experience which does not mimic or simulate the experience of person in a fictitious external real-world situation.

The ubiquitous real live reference to a box sliding down an incline so often mentioned in textbook chapters covering the concept of motion, Newton's laws and energy conservation is another example which is well suited for an Authentic (theory) experiment. A small wooden block is placed on a inclined melamine board and allowed to slide down. Again, students are not allowed to conduct the experiment but may watch the experiment as it unfolds. From visual inspection students may take note of the angle of incline and position of the wooden block. The task here is to determine the mass of the wooden block. Again, after identifying and applying Newton's laws correctly, or other suitable relations, the textbook guided calculations deviate from the actual wooden block's mass considerably. Again, a process of inquiry and immediate authentic and personal experience leads to a re-evaluation of the situation in front of them. On reflection, steps are then taken to include yet unaccounted for physical processes. In this case, the contribution of friction to the sliding needs to be somehow determined first before the actual mass calculation can be carried out.

A well informed authentic learning experience is one that is embedded in an operating workplace, e.g., in a work integrated learning period. In a work integrated learning environment, students are directly exposed the physical work environment with all its additional features (hardware, work divisions, skill sets), processes (safety, operations, task flows) and experienced workers on the task solving problems of real value (monetary, support). However, work integrated learning though is more suited for students with some demonstrated basic disciplinary knowledge and skills and conversely workplaces are more adapt to accommodate students at that level. In order to bring workplace experience and its immediate authenticity into the laboratory class, we created an "Authentic 
(hands-on)" laboratory program with an industry integration. So, rather than students being integrated in a workplace, we integrated an industry workplace into the curriculum design. That is, industry is directly involved in the design of authentic learning experiences through the creation of student experiments that closely resemble similar setups, aims and constraints as found at the actual industry workplace. The skill sets required to perform the experimental tasks and the applied disciplinary knowledge closely resemble those in the workplace. Another important aspect transferred from the workplace to the learning experience is the value or importance of the experiment and its outcome as benchmark for a credibility of the accomplished work. In this type of authentic learning experience students are assessed according their application of disciplinary knowledge, experimental design skills, data analysis skills, conciseness of their written professional reports and the usefulness of their findings.

We developed the authentic laboratory program for a first year undergraduate engineering course at the University of Technology Sydney where engineering students are required to take a one semester physics course (Physical Modelling). We invited Choice from industry to actively participate in the curriculum and experiments design. Choice is an independent consumer advocacy organization in Australian founded in 1959. Apart from being involved in the national policy making of consumer protection laws it also maintains a large accredited consumer products testing facility, on which the authentic laboratory program is modeled. Choice engineers also present in a lecture about their testing experiment process, from the commissioning of the work to the observation of international measuring standards. They also participate as casual observers during the laboratory classes. We were fortunate that Choice also provided us with a surplus of some of their already tested consumer products, which as per their testing policy they purchase as new products in local stores.

So, the role that students were asked to take on is that of a product testing engineer working in a small startup consulting company that is commissioned to investigate a particular consumer product. As commissioning third party students could choose from three fictitious agencies; a marketing company, a product manufacturer or government agency. The commissioning agency makes $\$ 2500$ available for testing, hiring of equipment and bench space and the production of a professional report including recommendations. This adds a certain value to the work that students do as well as sets a nominal benchmark for the quality of work that is expected.

As in the real-world industry, the experiments in these authentic learning experiences have no unique or common starting point. There are no pre-defined or prescribed to be measured experimental parameters and consequently there is also no set experimental measuring protocol. Since the task's aim only asks that a physical quantity backed solution should be presented, there is no pre-defined physical parameter to aim for.

In the real-world, one rarely finds multiple teams of engineers or scientists working in the same room separately and independently on the same problem (unless in some fund raising competition), they would quickly form a larger team and take advantage of the diversity of skills within the room. In translating this observation to the laboratory class room, many different types of consumer products were made available at the same time so that each laboratory bench is occupied with a different product, consequently very different types of experiment are carried out at each bench given the groups of student a sense of the uniqueness and originality of their approach. In practice, in our laboratory program for about 620 students in laboratory classes of about 40 each we have 12 teams of 2-3 students and 6 very different challenges for them to choose from. That means, that there are no more than two teams having a similar object as their experimental challenge. After six sessions all teams will have rotated through all challenges, although we generally limit this type of learning experience to three sessions to provide students an opportunity to also particate in a Traditional as well as an Authentic (theory) type of experiment.

Student teams work on up to six different commissioned projects. As each project and its product testing aim is entirely defined by the student team (including the selection of experimental methods and measuring tools/sensors) a high degree of critical thinking is required (client needs, social relevance, 
time constraints, physics concepts, experimental methods) and student teams are encouraged to take innovative approaches as they compete with other teams to meet the high expectations of their clients. Students here are placed in a real workplace scenario under workplace-like conditions and are rewarded for good multifaceted design and problem solving; innovative, complex and lateral thinking; and professional articulation of their presented results. An example assessment rubric can be found in the Appendix.

In focus groups conducted at the end of the teaching period students commented on the authenticity of their laboratory experience and the importance of the link between theory and its usefulness in real life, e.g., "When I'm doing the practical I get to experience different situations and where and how I can apply the theory to them. I love every single bit of it", and "I really appreciated doing real product testing. It was a taste of real engineering", and "It actually gives you a chance to put into practice what you are learning in the lecture theater and it's good because it's a bit different."

Students also appreciated and commented on the opportunity for experimental versatility as well as on the benefits of working in teams and having ownership over the their entire work, e.g., "Better than generic experiments that every other uni[versity] does," and "I found it helpful to work with a lab partner. It was good to learn from each other," and "It was really helpful to work in teams as more members means more ideas and more working hands. We could plan and implement ideas together."

We have not conducted a controlled comparative analysis to see whether this type of authentic learning experience improves student learning as measured by student performance because of the limited control we have over comparative student performance parameters in our program. There were also concerns about inequity between one class running an authentic experimental program and another class a benchmark traditional program. Further, these two types of programs address and assess different learning expectations (graduate attributes) which prevents a clear comparison of performance outcomes. Nevertheless, peeking in into one of our Authentic (hands-on) laboratory classes reveals an immediate and stark different atmosphere in the class. There is a buzzing activity throughout the class, all students are fully engaged in their activities and in deep discussions with their group members while the teachers in the room are almost invisible amidst the activities.

The Traditional, Authentic (theory) and Authentic (hands-on) learning experiences all were also subject of a parallel, independent kinesics guided proxemics study [20], which looked into the interactions between teacher and students in classes with group work. We made use of some of the data coming out of this study and present findings in the following chapter.

\section{Dynamics of laboratory learning experiences}

In an attempt to gain a more quantifiable understanding of the vastly different learning dynamics and student-teacher interactions which presented themselves so readily perceivable in the different types of laboratory classes, we attempted to capture the interaction learning pattern in the class using the Dimensions Observation Protocol (TDOP) tool developed by Hora [21]. The TDOP tool captures instructional practices, student-teacher interactions, and instructional technology through minute, direct observations and recording of the presence of key activities within the class room. The software tool has a large number of interaction and other activities to choose from and when identified as present in the class room at a particular time, its occurrence time, duration and frequency is recorded by each time the observer clicks a respective activity button. This kind of observation seemed to work well for a traditional or inquiry enhanced traditional type of laboratory class as long as the observer focused on only a handful of student-teacher interaction types and as long as students conducted the experiments very much in sync along a prescribed pattern that meets the class timetable. This kind of active class observation is quite an intense exercise for the observer. Further, each observer has to undergo a rigorous training to ensure observations of interactions and the interpretation of their nature is recorded consistently. This type of observation regime proved to be unmanageable for our Authentic (theory) and Authentic (hands-on) classes because of the large number of interaction types that are present at the same time and the asynchronous organization of experiment activities. 
Instead we decided to engage in a pilot with a monitoring approach that does not depend an observer in the room and an immediate interpretation of the ongoing observation. For that purpose we invited Dr Roberto Martinez-Maldonado from the Connected Intelligence Centre at the University of Technology Sydney to use our laboratory classes for his kinesics guided proxemics study on class room group work design and teacher reflection. Our hypothesis was that some of the data from this proxemics study might also give us more insight into the characteristics of the different learning experiences in our laboratories and the dynamics within the class.

Proxemics studies the use of physical space in social interactions, kinesics focuses on body movements and how these may affect communication [22]. Translating these social interaction to our laboratory classes, the proximity of a teacher to particular student group during class and the frequency of visiting the group tells a story about the attention that the teacher is giving a particular group. It also indicates the need of the student group for attention or teacher advise. The time averaged intervals of the teachers spatial positions in class shows us the paths that teachers take to navigate through the class amongst students and their experiments. It shows where across the room the teachers' advise is requested most and where student-teacher interaction occurs away from the experimental setup or in front of a white-board.

Figure 1 shows so called heatmaps of kinesics guided proxemics measurements taking in each one of our Traditional (top), Authentic (theory) (middle) and Authentic (hands-on) (bottom) during the third quartile period (left column) of a two and half hour laboratory class and the aggregated time summary of over the entire class period (right column) [23].

For the proxemics measurement, the teacher and teacher assistant are equipped with the location sensors which are tracked by a sensor tracking array of six detectors mounted at the class room walls. Positions were tracked real-time at a rate of about $2 \mathrm{~Hz}$ and during post-processing normalized to one second intervals for better visual inspection. Thus, each orange (teacher) or blue (teacher assistant) circle (Fig. 1) represents their respective average positions within a one second interval. Naturally, this kind of time averaging attracts a triangulation error which in our case is around $20 \mathrm{~cm}$. The large red dots indicate experiments that have been set up at or close to the lab benches. As guidance for the general scale of the laboratory and distances, the lab benches are $1.2 \mathrm{~m}$ wide and $6 \mathrm{~m}$.

The recordings shown in Figure 1 are all of the same class, i.e., the same students in class sitting at approximately the same relative position at their benches and the same teachers supervising the class.

The first row in Figure 1 shows the proxemics results of the real-time teacher position monitoring of the Traditional learning experience during the third quartile of the lab session (left) and over the entire period of lab class (right). The monitoring data was segmented in four quartiles to distinguish four general periods of class activity; the introduction and getting ready period, the coming to terms with the experimental work period, the middle of the experimental work period; and the experiment conclusion and cleaning up period. The third quartile period was chosen here to look at each learning experience when it is generally in full swing, that is from half way into the class period.

In the third quartile of the class period we can see that many student groups still require intense consultation with teachers or request their attention although the Traditional learning experience was guided by well defined step-by-step instructions in the lab manual which outline the sequence of actions to take as well as how these are to be executed. It appeared that the prescribed instructions that were given are prompting student requests to provide even more detail instructions or to seek assurance for the correctness of each small step they take. This may suggest that the learning experience was more focused on following instructions and collecting data points and less on reflection and concept discussions within the small groups. The teacher proximity heatmap for this entire class (right) shows how teachers moved from team to team and had to spend a long time with each of the teams. It can 

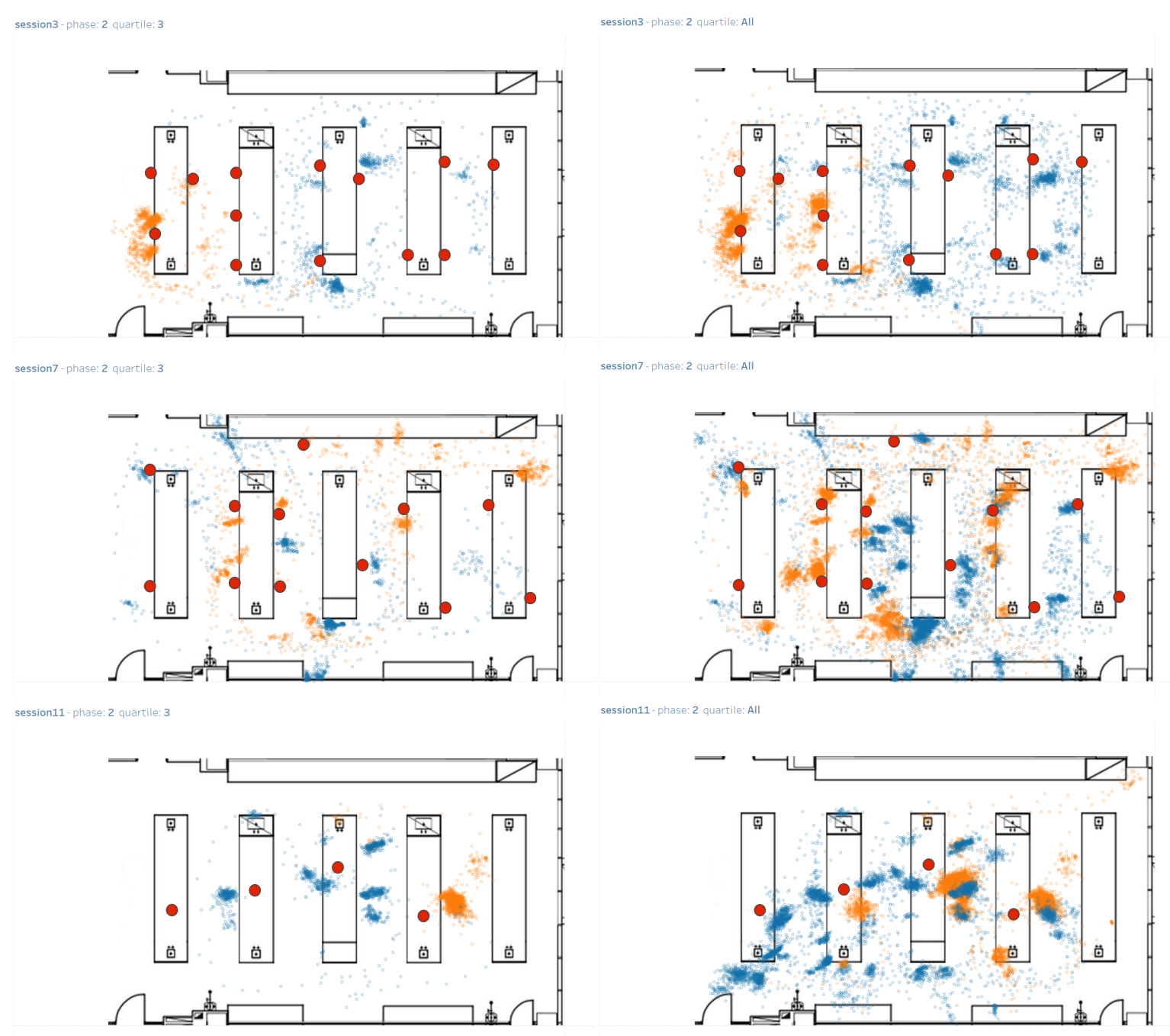

Figure 1. Schematic of the laboratory class showing the recorded session dynamics[20] of a Traditional (top row), Authentic (hands-on) (middle row) and Authentic (theory) (bottom row) laboratory learning experience of the same class. The images on the left show dynamics of teacher movements recorded just during the 3rd quartile of the session, the images on the right show the dynamics aggregated over the entire class duration. They large red dots indicate the location of experiments, blue and orange circles indicate the locations that the teacher and teaching assistant frequented most.

also be seen that the teachers split up their spatial coverage of the class to meet consultation demand with one teacher serving the left part of the class and the other one the right part.

The second row in Figure 1 shows the results of the position monitoring in the Authentic (hands-on) learning experience. A first, cursory visual inspection shows that the teachers in this class experienced quite a different interaction pattern with the students groups. Compared to the Traditional learning experience, here quite some time is spent away from the benches and away from direct attention to the physical experiment. One teacher (blue circles) is frequently seen close at the classroom wall where there is a white board. Both teachers are recorded to spent time in normally less occupied spaces away from the experiments. This indicates that teachers no longer spent most of their time assisting students close to their experiments with requests for step by step instructions or laboratory notes, instead interactions are occurring away from experiment locations and student laboratory notes. Students take initiative to move away from their experiment to meet the teacher somewhere in the room to discuss their plans, ask for the availability of a particular measuring device or discuss professional quality 
issues regarding their experiment and report. Inquiries are no longer procedure or lab manual centered and hence can be articulated freely and away from the experimental setup. Teachers also don't seem to walk in a pattern from experiment to experiment on students' request or to check on correct procedural sequences, instead they spent most of their time in the larger class space where students can approach and engage in discussions as needed. Since discussions occur away from the experiment location, experiment procedural and detail are no longer a primary focus of student-teacher interaction. A more freely and widely distributed teacher motion pattern also indicates that students have taken more ownership of their work as teachers are no longer requested to attend individual groups at their experimental set up.

The bottom row in Figure 1 shows the position monitoring of the Authentic (theory) learning experience. Here, the teachers' motion pattern are again very much different from the other two learning experiences, though there are some feature shared with the Authentic (hands-on) motion pattern. To explain the differences, we recall the characteristic setup of this type of learning experience. In the Authentic (theory) learning experience, students actually don't set up or conduct an experiment, instead they are asked to develop their own model to predict the outcome of four different experiments that are on display. That is, the four locations of the experiments (large red dots) shown in the images are no longer related to the bench location where student teams are sitting. Student teams though still sit appropriately at the same locations as shown in the other learning experiments. So, students walk up to the display experiments to have a closer look or take some rough measurements of an experiments geometric features if needed. There are clearly two spots of proxemics concentrations where teachers move frequently and spent most of their time. One is close to the display experiments where they may engage with students in discussions about their theoretical model or later in the session conduct the experiment on students' request to test their model predictions. The other location is away from the display experiments. This indicates that students feel content to work independently in their small teams and trying to raise up to the challenge of proving their theoretical model, i.e., without the frequent request for teachers' attention to confirm steps or procedures. Again, discussions are being held away from experiment locations, which indicate that in those discussions no pointing to the experiment or working notes at the bench are required to conduct these discussion, i.e., discussions are held in a larger disciplinary context driven by student interest and engagement.

The interpretation of the kinesics guided proxemics heatmaps in Figure 1 are of course very much informed by our good knowledge of what actually happens in these laboratory classes and the nature of communications that students usually have with their teachers and team members. Prior to the independent monitoring of the student-teacher interaction the evaluation of learning experiences relied on teachers' subjective and qualitative or anecdotal type of interpretation of what happened during class (procedural driven, "more buzzing"), or on subjective student comments in student feedback surveys or feedback in focus group sessions where a small number of students are asked about their level of engagement or learning experience the laboratory classes. With the kinesics guided proxemics heatmaps we are now one step closer to quantify differences in laboratory learning experiences independently of the actors participating in it and independent of a direct observer's interpretation of a particular interaction characteristic. Further exploration of the large amount of data accumulated in this study may lead us to a formulation of teacher and student independent quantitative indicators for types of learning experiences in laboratory classes and level of independent learning, which might be useful for the monitoring of impacts of future changes to the program or other pedagogical interventions.

\section{Authenticity with industry collaboration in mind}

The redesign of a the large first semester laboratory program from a traditional inquiry based program to a sustainable, authentic learning experience that closely resembles a professional work 
place in industry requires some steps that need to be considered carefully and well in advance of the program's implementation. This chapter presents some the considerations we made in the processes of creating an authentic learning experience close to what a graduate would experience in industry workplace.

Our starting point was an inquiry based laboratory program that followed traditional laboratory teaching pedagogy with step-by-step experimental task descriptions and scaffolded, prescribed methods for collecting data and presenting results. As it is often the case in inquiry laboratory programs, the inquiry components of experiments often relate to connecting the steps of each task and finding out how to handle or operate the bench dedicated equipment, i.e., experiments can be conducted with little or no preparation before the lab class.

There are a number of high-level aspect to consider in the redesign process. The redesign of any large undergraduate laboratory program irrespective of the pedagogical aims can be a very time and resources consuming undertaking. Even more so if a redesign goes beyond marginal changes to experiments or a replacement. Sustainability and further scalability is another important factor to consider since resources need to be committed long term and a new program should not be easily compromised by fluctuations in student numbers.

The practice we followed in the past when making changes to our laboratory programs was to introduce marginal changes to selected experimental setups (modernizing equipment), making evidence based pedagogical adjustments to experimental procedures (change from procedural to inquiry focus; identical experiment kits) or recycling suitable experiments from another laboratory program. Most of our experiments evolved from classical, procedure driven experiments with a central focus on verifying prominent aspects of a physics concept or exploring a functional relationship between respective concept inherent parameters. The experiments of these type of learning experience served their respective pedagogical goal and were not suitable to be turned into a real work place simulating, authentic learning experience. A further constraint in changing to authentic industry related activities is that academics and laboratory support staff are not experts in workplace practices, common workplace infrastructure and workplace processes.

Since the expectation was set for the new undergraduate laboratory program to become an authentic learning experience that closely resembles a professional work place, a suitable industry needed to be identified that can consult on workplace tasks, authentic experiments and laboratory processes. The redevelopment of an entire laboratory program, including all experiments, requires substantial human and financial resources. With resource constraints and sustainability well in mind, and our limited expertise in industry practices, it became evident that a successful conversion to an authentic experimental laboratory program cannot be achieved without industry closely engaged in the curriculum development, participating to some degree in the delivery of the program and its evaluation, and having some self interest in being involved in the process. This became the starting point for the planning of our developing journey.

The following is a summary of the process steps and considerations that in retrospect we found essential for the program's development, implementation and its routine execution. It may serve as guidance for similar laboratory program developments.

\subsection{The High-level Planning}

The high-level planning is concerned with general issues arising at the interphase between university and industry, and what university and industry may expect from each other.

\subsubsection{Identify industry practice suitable for embedding authentic learning experiences}

Most academic environments at undergraduate level use equipment and ask for task processes that are quite different from normal industry practices. Even where experimental equipment is identical, the purpose of the experiment in industry and the motivation to conduct the experimental task may have little to do with the task focus in a first year undergraduate laboratory or only cover a 
very small part of the curriculum requirements or are beyond the disciplinary knowledge and skills at that level.

\subsubsection{Identify suitable industry for course support}

'Industry' is a wide carrying expression and often industry from an academic perspective is a specific, idealized, almost stereotyped, future working place of an ideal graduate. In addition, graduates usually find employment in areas peripheral to their degree discipline. Thus, a potential industry partner needs to be vetted not only for vicinity to course content but also for the suitability of their actual working practices for undergraduates at first year level.

5.1.3. Design of student engaged learning activities to support content of laboratory work, course outcomes and graduate attributes

Particular experiments and tasks carried out in industry are usually not stand alone activities but a small contributing step within a larger context of a goal to be achieved. We found this larger context to be an essential attribute of an authentic laboratory activity. The larger contexts ties in with disciplinary and experimental skills that are to be developed as well as other learning outcomes such as graduate attributes. This design aspect narrows down the number of potential industry workplaces that would normally come to mind immediately. On the other hand, it also opens up opportunities to look into industry and workplaces that one would normally not associated directly with the discipline.

\subsubsection{Timeframe and Timetabling}

The academic logistics surrounding the redesign of any laboratory program usually follows a well-treated path, although by no means without the equally usual bumps. In contrast, industry follows industry practices and unforgiving industry timelines. The industry partner under consideration should have the capacity work along university timelines and, if industry staff is involved in some teaching activities, some capacity to release staff for that purpose should be available during the planning period as well as at required university set teaching times.

\subsection{Embedding Authenticity}

\subsubsection{What disciplinary knowledge (concepts) are students expected to learn?}

The answer to this question is to a large extend prescribed by the degree course content, in particular in first year which develops the foundation knowledge for subsequent courses. In the context of an industry collaboration though, the question arises whether the targeted industry is exposed to all, some or only one of the first year disciplinary concept. If authentic learning experiences are to be embedded in an entire laboratory teaching program, ideally work practices at the industry partner ought to cover all concepts that the laboratory program covers. Otherwise, multiple industry partners will be need which adversely impacts on logistic alignment as well as long term sustainability of the program.

\subsubsection{What practical skills are students expected to learn?}

Practical skills in first year undergraduate laboratory programs are the very reason why these programs exist. Yet, the specific practical skills to be learned are often not well articulated in the curriculum and rarely assessed in their detail. It is more the outcome of the process of conducting an experiment that is assessed rather than particular experimental skills. In that sense, conducting an undergraduate experiment is then about learning about experimental procedures with, in our case), physics concepts as contextualizing backdrop. Processes and procedures in undergraduate experiments are generally disjunct from actual practices in the workplace. Putting on goggles, gloves and lab coats and being mindful of occupational health and safety may be seen as simulating a professional 
environment, but is only a ritual to be performed before the actual professional work may start. The skills that we expect first year students to learn are the professional skills that are routinely applied in industry today.

\subsubsection{First year undergraduate skills used in industry in a non-trivial way}

By their final year, closer to graduation, students have acquired advanced disciplinary knowledge and skills and, hence, are in the position to conduct more sophisticated experiments and have been trained to operate more sophisticated, high-end equipment which may also be found in high-end industry. At first year undergraduate level, fundamental disciplinary concepts are still in the process of being developed. The question arises then, where in industry are all or some these concepts routinely applied in practice?

\subsection{Suitable industry partner}

5.3.1. Are the industry partners under consideration sufficiently resilient to maintain long-term collaboration?

Common aspects to consider about the sustainability of a large first year university undergraduate laboratory teaching program are whether required human and financial resources can be maintained over the lifetime of the program and can adapt to student cohort size fluctuations without compromising the program; and how long physical laboratory resources can last and whether all consumables will be available over the period of the program. In a teaching program and teaching pedagogy related interaction with industry, the desired period of continuous collaboration with industry is likely be longer than e.g. one would see in a technology development relation at the graduate or professional academic research level. The industry partner should be large enough so that the different seasonal cycles of operations between the university laboratory program and industry have little impact on the functional operation within their institution. Other factors to consider are sufficient financial stability, staff turnover rates and whether the industry unit, department or division size is large enough or has long term capacity to support a relation with a non-core business partner (university) on non-revenue generating activities. Restructure within the industry organization may place the undergraduate laboratory program at risk.

\subsubsection{Suitability of industry}

The disciplinary knowledge and skills requirement in a first year physics (or any other) experimental undergraduate program are very basic and generally far away from the knowledge and skills that are applied in the professional industry. On the other hand, the application of basics science, technology, engineering or maths skills can be found in almost all industry, not just the one that universities deal with at graduate of research level. For our objectives we ruled out Government run national research laboratories. Although, in numbers, national research laboratories are the largest sector industry that academia in Australia is collaborating with, only a very small number of graduates will find their employment there. Government though comprises a number of policy enforcing agencies such as environmental protection and law enforcement, and service agencies in transport, hospital and work safety, all of which might have an interest in early engagement with future graduates. Manufacturing is a term that spreads across a large range of sub-industries. Basic concepts of physics are applied in many production stages in the automobile, construction, food, textile, recycling and mining industry to name but a few. Other industries such service, financial and legal don't come readily to mind when in the context of first year university physics and engineering, yet a large proportion of graduates find employment in these sectors. Further, applications of basic physics concepts in those sectors rarely find their way into lecture and laboratory teaching material. An industry partner from the service industry may have a mutual interest to be involved in a physics undergraduate laboratory program, e.g., a maintenance company (elevators, factory machines, bridges, buildings); insurance 
evidence verification in financial industry; or a large patent offices in the legal industry. One industry sector that is one of the most heterogeneous and yet often not seen as being part of what academics think of "industry" are the Not-for-Profit Organization (NPO) and Non-Government-Organization (NGO) sector. This sector engages in activities found in almost every area of industry. For instance, NPOs and NGOs engage in engineering support in developing countries, practical aspects of environmental protection and consumer protection. In our case, it turned out that the consumer protection industry was an ideal candidate for our authentic laboratory program. While identifying a good match after a long process of searching and elimination, the educator's view of an ideal may not necessarily meet the potential industry partner's view. In addition to the educators set program requirements another normally in education not often considered aspect has to be considered, the potential benefit of this program to the industry.

\subsubsection{Is there sufficient mutual benefit for a long-term collaboration?}

Here, we are interested in a collaboration of mutual benefit at first year undergraduate level, not in revenue generating research outcomes of mutual interest. The educational and pedagogical value that direct industry collaboration can bring to a first year experimental science program in terms of curriculum development, special lectures and possibly experimental equipment, sponsorships and awards are obvious. Industry in turn may benefit from the brand affiliation with the university, low cost top-level professional development opportunities for staff, marketing opportunities, brand expansion to a younger audience, long term access to a large volume of experimental results, access to innovative approaches and new ideas.

\section{Conclusions}

Students and educators may have different views on the authenticity of the science in action in their laboratory programs. In the end we find that the benchmark for assessing the level of authenticity always lies with the practitioner in the workforce because it is the science in the real world performed by real practitioners that we wish students to relive in the student laboratory as close as possible. Yet, an important factor in the learning experience is how students perceive authenticity in the laboratory environment. It is not just the experiments and experimental processes that we expect to be authentic, there is also a high level of emotional authenticity that goes along with the experience. The creation of a sense of importance, the validity and value of the task, and the level self-determination, ownership and reflective responsibility are all important factors in the design of an authentic laboratory program.

We explored some typical laboratory designs and noted three pedagogical shifts in designs, from what we called traditional to the traditional topped up with elements of inquiry and the authentic program design. In essence, all these types of experimental programs are striving for an authentic learning experience, albeit in different pedagogical context. What is believed to be authentic in a laboratory experience changed over time along with the changes in technology, workforce practices and education policies trying to adjust for changing graduate attributes. The changes though occurred distinct larger steps more in line with the university and educational policy cycle and inertia rather than changes in the professional workforce landscape and practices.

We outlined the characteristic features of what we termed here as traditional laboratory experience, which at the time may have been viewed as authentic since it was close to educators' own laboratory experience as well as suited their desired graduate attributes. The later introduction of a degree of inquiry in these experiments allowed for some student curiosity and reflection which helped to keep students' interest up.

There is quantum leap between a traditional experimental program (inquiry or not) and today's types of authentic laboratory programs. A leap not only in the types of experimental activities that have been developed but also in the expected discipline attributes. With the rapid advances in communication technology around the turn of the millenium, such leap comes to no surprise. Students within the same course are now trained for a much larger variety of workplaces and workplace 
situations. They are expected to be ready for the workforce from the get-go, not only discipline factually (traditional discipline knowledge) but also profession emotionally (communication, reflection, responsibility, ethics)

We presented another form of authentic learning experience (Authentic (theory)) that we specifically created to provide for a reflective hands-on experience of textbook theory, an aspect of discipline knowledge and experience that we found missing in the other two types of laboratory programs.

We identified characteristic features of these three laboratory programs. The main differences between the traditional experimental program and what we perceive today as authentic is the level of responsibility and ownership that students have to plan and execute their task and the credibility of experiments and experimental tasks.

We also asked the question whether it is possible to quantify the level of authenticity in a laboratory program, i.e., we were looking for indicators that could be used to quantify characteristics of authentic learning experiences that could be used for observer independent evaluation of future laboratory programs. A proxemics based analysis of a Traditional, Authentic (hands-on) and Authentic (theory) learning experience presented us with a participant independent image of the student-teacher interaction. The visualization of the proxemics measurements in the different types of laboratory designs provided us with some more insight into student-teacher interactions, learning activities and intended learning experience. It revealed a serious short in the intended learning experience in the Traditional laboratory where it was thought that providing detail, written step-by-step instructions would assist students to focus on the disciplinary content and context, yet indicated that students where more concerned about step procedures to complete the task. In the Authentic learning experience in became evident that an intended elevated level of student engagement and independent working can be identified without the presence of an observer or subjective feedback by teachers or students. This first result of the proxemics measurement showed that distinct features of laboratory experiences can be identified and differentiated, which is an important step and pre-cursor for the possibility of formulating characteristic indicators for authentic learning experiences in a continuation of this research.

Funding: This work has been supported in parts by a University of Technology Sydney (UTS) Faculty of Science SciMERIT 2017 grant.

Acknowledgments: The author is grateful to Dr Islam Hedayetu for a literature research on laboratory class observation tools and the Teaching Dimensions Observation Protocol (TDOP) and to Dr Roberto Martinez-Maldonado from the UTS Connected Intelligence Centre at the University of Technology Sydney for providing the data from his proxemics measurements.

Conflicts of Interest: The author declares no conflict of interest. The funders had no role in the design of the study; in the collection, analyses, or interpretation of data; in the writing of the manuscript, or in the decision to publish the results. 
724 Appendix.

Authentic (hands-on) Assessment Rubic.

725

\begin{tabular}{|c|c|c|c|c|c|c|c|}
\hline \multirow{2}{*}{ 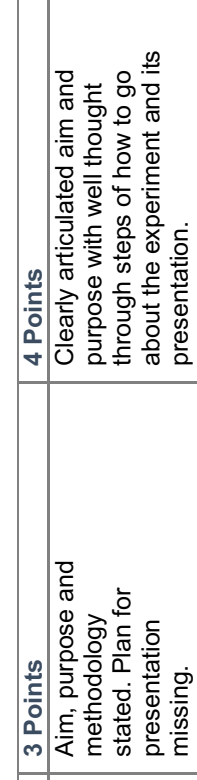 } & & 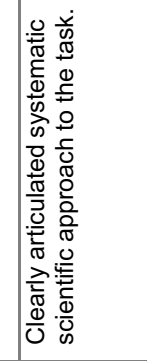 & 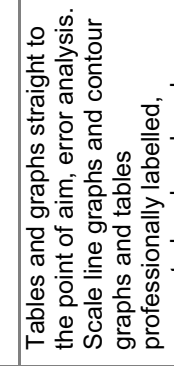 & 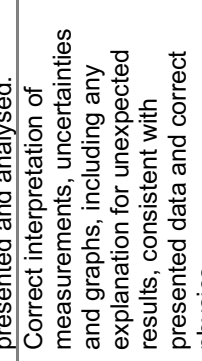 & 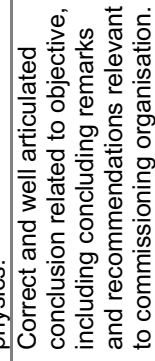 & & \\
\hline & 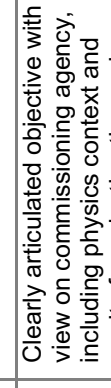 & 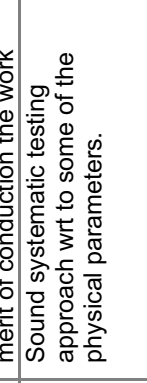 & 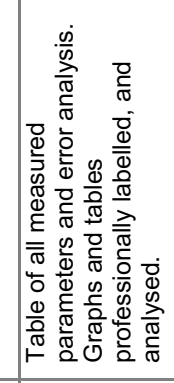 & 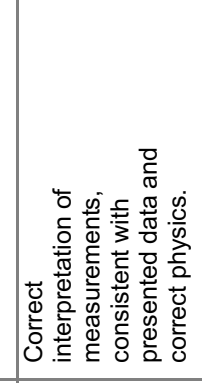 & 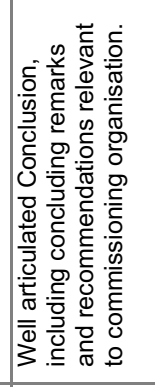 & & \\
\hline 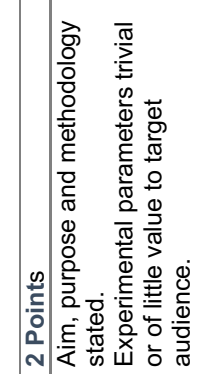 & 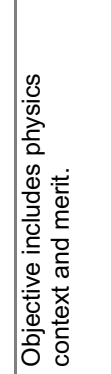 & 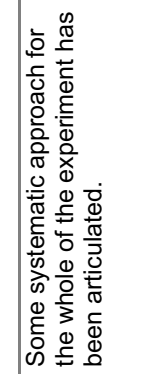 & 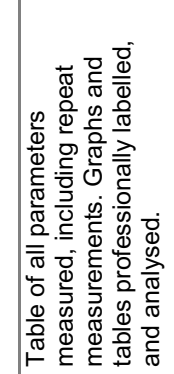 & 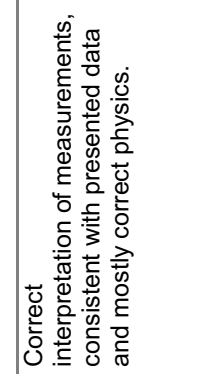 & 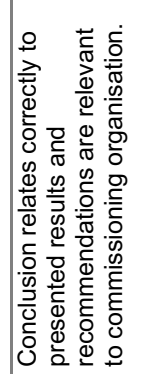 & & \\
\hline 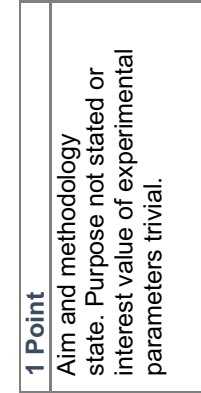 & 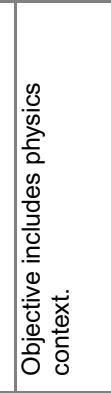 & 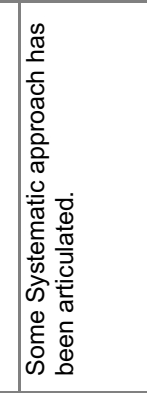 & 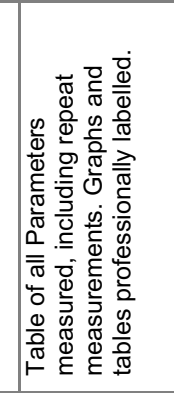 & 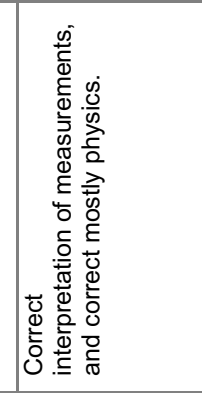 & 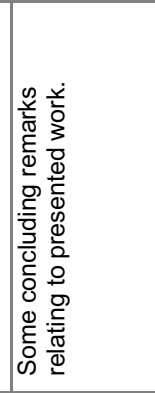 & 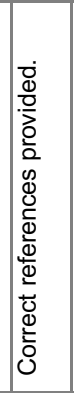 & 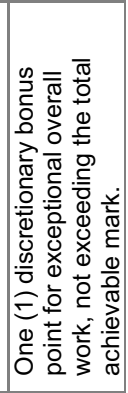 \\
\hline 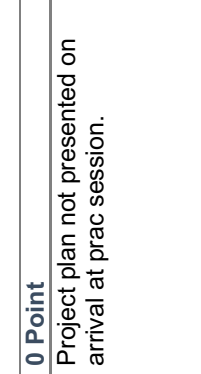 & 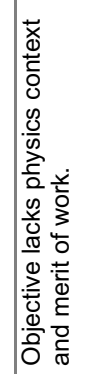 & 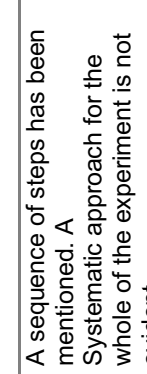 & 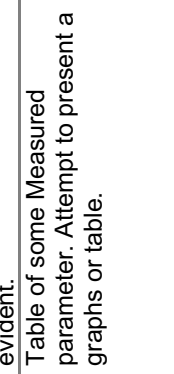 & 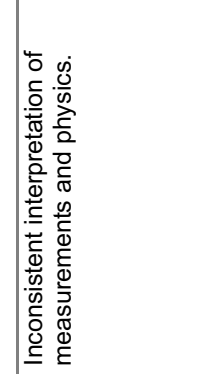 & 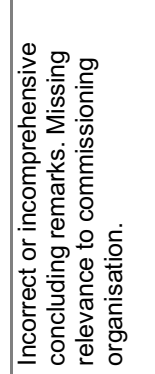 & 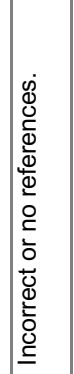 & 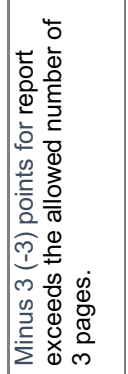 \\
\hline 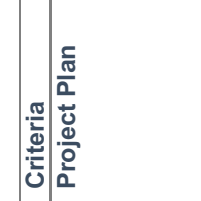 & 总 & 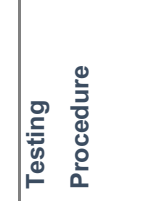 & 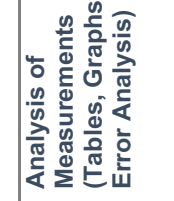 & 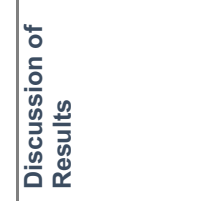 & 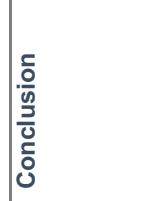 & 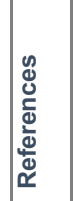 & 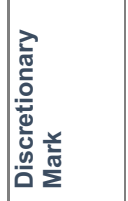 \\
\hline
\end{tabular}




\section{References}

1. Levin, E., Salehi, K. Graduate attributes: what are they and how do we know if students can achieve them?. In Lifelong learning: Whose responsibility and what is your contribution?; P. A. Danaher, C. Macpherson, F. Nouwens, and D. Orr (Eds.); Proceedings of the 3rd International lifelong learning conference, Yeppoon, Queensland, Australia , 13 - 16 June 2004; pp. 211-217, http:/ / hdl.cqu.edu.au/10018/1762

2. For an overview of graduate attributes and the graduate framework see: https://www.uts.edu.au/researchand-teaching/learning-and-teaching/uts-model-learning/graduates-attributes

3. Reeves, T.C., Herrington, J., Oliver, R. Authentic activities and online learning. In Quality conversations: Research and Development in Higher Education 2002; HERDSA Proceedings, Herrington T. (ed.) 25, pp. 562- 567

4. Donovan, M.; Bransford, J.; Pellegrino, J. How people learn: Bridging research and practice, committee on learning, research and educational practice. National Research Council: Washington, DC, USA, 1999; pp. 1-78; ISBN 978-0-309-18584-4.

5. Van Vorst, H., Dorshu, A., Fechner, S., Kuertz, A., Krabbe, H., Sumfleth, E. Charakterisierung und Strukturierung von Kontexten im naturwissenschaftlichen Unterricht - Vorschlag einer theoretischen Modellierung (Characterization and scaffolding of context in science education - A Theoretical Model). Zeitschrift für Didaktik der Naturwissenschaften 2014 21(1), 29-39

6. Brown, J.S., Collins, A., Dguid, P. Situated cognition and the culture of learning. Educational Researcher 1989 (18)1, 32-42

7. Newmann, F., Mark, H., and Gamoran, A. Authentic Pedagogy: standard that boost the students' performance. Issues in Restructuring Schools 1995, 8, pp. 1-12

8. Maina, F. W. Authentic Learning, Perspective from contemporary educators. Journal of Authentic Learning 2004 (1)1, pp. 1-8

9. Jonassen D.H. Context is everything. In: Educational Technology 1991, (31)6, pp. 35-37

10. Bennett, J., Hogart, S., Lubben F. A systematic review of the effects of context-based and Science-Technology-Society (STS) approaches in the teaching of secondary science. EPPI-Centre, Social Science Research Unit, Institute of Education 2003, University of London.

11. Bennett, J., Lubben F., Hogart, S. Bringing science to life: A synthesis of the research evidence on the effects of context-based and STS approaches to science teaching. Science Education 2007, (91)3, pp. 347-370

12. Voogt, J., Roblin, N. P. A Comparative Analysis of International Frameworks for 21st Century Competences: Implications for National Curriculum Policies. Journal of Curriculum Studies 2012 44, pp. 299-321, doi:10.1080/00220272.2012.668938

13. Sawyer, K. The Cambridge handbook of the Learning Sciences 2006. New York, NY: Cambridge University Press.

14. Handelsman J., Ebert-May D., Beichner R., Bruns P., Chang A., DeHaan R., Gentile J., Lauffer S., Stewart J., Tilghman S.M., William Wood W.B. (2004). Science Teaching. Science 2004, 23(304) 5670, pp. 521-522, doi: 10.1126 /science.1096022

15. Herron, S. From cookbook to collaborative: Transformation a university biology laboratory course. American Biology teacher 2009, 71(9), pp. 548-552

16. Wood, W. Innovation in teaching undergraduate biology and why we need them. Annual Review of Cell and Development Biology 2009, 25, pp. 93-112

17. Hart, P. How should colleges prepare students to succeed in today's global economy? Online bf 2006, http:/ / www.aacu.org/leap/documents/Re8097abcombined.pdf

18. Skinner, R. and Cowan, E. Authentic Assessment: Project for the Future. ERIC Document Reproduction Service 1995. No ED 392611.

19. Sawyer, K. Optimising Learning: Implications of Learning Sciences Research. OECD/CERI International Conference Learning in the 21st Century: Research, Innovation and Policy 2008, Paris (France), pp 1-14

20. Martinez-Maldonado, R., Echeverria, V., Santos, A., Santos, O., and Yacef, K. Physical Learning Analytics: A Multimodal Perspective. International Conference on Learning Analytics and Knowledge bf 2018, LAK 2018, pp. 375-379

21. Hora, M.T. Toward a Descriptive Science of Teaching: How the TDOP Illuminates the Multidimensional Nature of Active Learning in Postsecondary Classrooms. Science Education 2015 (99)5, pp. 783-818

22. Sorokowska, A. et al. Preferred Interpersonal Distances: A Global Comparison. Journal of Cross-Cultural Psychology 2017 
778 23. Figure 1 images courtesy Roberto Martinez-Maldonado. Proxemics recordings of first semester physics 779 laboratory classes. Private communication 2018. Connected Intelligence Centre, University of Technology 780 Sydney. 